\title{
Universiteit
}

Leiden

The Netherlands

\section{Transcription of the sporulation gene ssgA is activated by the IclR- type regulator SsgR in a whi-independent manner in Streptomyces coelicolor A3(2)}

Traag, B.A.; Kelemen, G.H.; Wezel, G.P. van

\section{Citation}

Traag, B. A., Kelemen, G. H., \& Wezel, G. P. van. (2004). Transcription of the sporulation gene ssgA is activated by the IclR-type regulator SsgR in a whi-independent manner in Streptomyces coelicolor A3(2). Molecular Microbiology, 53(3), 985-1000.

doi:10.1111/j.1365-2958.2004.04186.x

Version: $\quad$ Publisher's Version

License: $\quad$ Licensed under Article 25fa Copyright Act/Law (Amendment Taverne)

Downloaded from: https://hdl.handle.net/1887/3217772

Note: To cite this publication please use the final published version (if applicable). 


\section{Transcription of the sporulation gene $s s g A$ is activated by the IcIR-type regulator SsgR in a whi-independent manner in Streptomyces coelicolor A3(2)}

Bjørn A. Traag, ${ }^{1}$ Gabriella H. Kelemen ${ }^{2}$ and

Gilles P. van Wezel ${ }^{1 *}$

${ }^{1}$ Department of Biochemistry, Leiden University, PO Box 9502, 2300RA Leiden, the Netherlands.

${ }^{2}$ School of Biological Sciences, University of East Anglia, Norwich NR4 7TJ, UK.

\section{Summary}

SsgA plays an important role in the control of sporulation-specific cell division and morphogenesis of streptomycetes, and ssgA null mutants have a rare conditionally non-sporulating phenotype. In this paper we show that transcription of $s s g A$ and of the upstream-located $s s g R$, an iclR-type regulatory gene, is developmentally regulated in Streptomyces coelicolor and activated towards the onset of sporulation. A constructed $s s g R$ null mutant was phenotypically very similar to the $s s g A$ mutant. The absence of $s s g A$ transcription in this mutant is probably the sole cause of its sporulation deficiency, as wild-type levels of sporulation could be restored by the SsgR-independent expression of $s s g A$ from the ermE promoter. Binding of a truncated version of SsgR to the ssgA promoter region showed that $s s g A$ transcription is directly activated by SsgR; such a dependence of ssgA on SsgR in S. coelicolor is in clear contrast to the situation in S. griseus, where ssgA transcription is activated by A-factor, and its control by the SsgR orthologue, SsfR, is far less important. Our failure to complement the ssgR mutant with $S$. griseus $s s f R$ suggests functional differences between the genes. These observations may explain some of the major differences in developmental control between the phylogenetically divergent species $S$. coelicolor and S. griseus, highlighted in a recent microreview (Chater and Horinouchi (2003) Mol Microbiol 48: 915). Surprisingly, transcription of $s s g A$ and $s s g R$ is not dependent on the early whi genes (whiA, whiB, whiG, whiH, whil and whiJ).

Accepted 19 April, 2004. *For correspondence. E-mail g.wezel@chem.leidenuniv.nl; Tel.(+31) $715274310 ;$ Fax (+31) 71 5274340 .

(C) 2004 Blackwell Publishing Ltd
Introduction

Streptomycetes are soil-dwelling Gram-positive bacteria that have an unusually complex life cycle, which makes them particularly interesting for the study of bacterial development and evolution (Chater and Losick, 1997). During its life cycle, Streptomyces undergoes two apparently different events of cell division (reviewed in Flärdh and van Wezel, 2003). Initially, cell division results in the formation of semipermeable septa in the vegetative hyphae ('crosswalls') that delimit the multinucleoid hyphal cells. In solid-grown cultures, the reproductive phase is initiated by the formation of an aerial mycelium, with initially aseptate hyphae; in a later sporulation-programmed stage many septa are simultaneously formed, eventually resulting in mono-nucleoid spores (Chater, 2001). Recently, the genome sequences of $S$. coelicolor and $S$. avermitilis were elucidated, taking Streptomyces research into the genomics era (Bentley et al., 2002; Ikeda et al., 2003).

Genes involved in the transition from vegetative to aerial mycelium are called bald (b/d) genes, characterized by the bald appearance of mutants as a result of their failure to produce aerial hyphae, and those involved in the subsequent processes leading to sporulation, are white (whi) genes, characterized by the white appearance of mutants resulting from failure to complete sporulation. Six whi loci, designated whiA, whiB, whiG, whiH, whil and whiJ, identified by Chater (1972), are essential for the sporulation process (Flärdh et al., 1999). The best characterized of these sporulation genes are whiG, encoding an RNA polymerase sigma factor (Chater et al., 1989); whiB, encoding a transcription factor with many homologues in streptomycetes and mycobacteria (Soliveri et al., 2000), and whiH, encoding a GntR-family transcription factor (Ryding et al., 1998). The whiH mutant is phenotypically similar to a mutant in which the developmental $\mathrm{fts} Z$ promoter had been inactivated (Flärdh et al., 2000).

Recently, Chater and Horinouchi (2003) compared the developmental regulatory cascades in Streptomyces coelicolor and Streptomyces griseus. These two organisms probably diverged from a common ancestor around 200 million years ago (Embley and Stackebrand, 1994) and an important difference between them is that $S$. gri- 
seus sporulates in submerged culture. The signal for the onset of this still poorly understood process is the production of the $\gamma$-butyrolactone A-factor. In S. griseus, A-factor plays a more direct role in developmental control than the highly similar $\gamma$-butyrolactones (called SCBs) found in $S$. coelicolor. Whereas A-factor non-producing mutants of $S$. griseus are defective in development and antibiotic production (reviewed in Horinouchi, 2002; Chater and Horinouchi, 2003), these processes seem barely affected in $\gamma$ butyrolactone-deficient mutants of $S$. coelicolor (Takano et al., 2001).

One of the key targets of A-factor in S. griseus is $s s g A$ (Yamazaki et al., 2003), a gene encoding a protein unique to sporulating actinomycetes that was originally identified as an effecter of cell division in S. griseus (Kawamoto and Ensign, 1995). SsgA plays an activating role in the production of sporulation septa, as its enhanced expression in $S$. coelicolor resulted in fragmentation of the mycelia in submerged cultures, producing spore-like compartments at high frequency (van Wezel et al., 2000a). ssgA mutants of $S$. coelicolor and $S$. griseus are defective in sporulation, but form apparently normal vegetative septa (Jiang and Kendrick, 2000; van Wezel et al., 2000a). In total seven $s s g A$-like genes ( $s s g A-G$ ) occur in $S$. coelicolor and six in $S$. avermitilis (Flärdh and van Wezel, 2003). The ssgB gene was recently identified as a novel whi gene and a null mutant produced large non-sporulating colonies (Keijser et al., 2002).

Upstream of $s s g A$ lies $s s g R$, a member of the family of $i c / R$-type regulatory genes. This family includes IcIR itself, the repressor for the isocitrate lyase gene (Sunnarborg et al., 1990) and the acetate utilization operon (Galinier et al., 1990) in E. coli, and the glycerol regulon repressor GyIR in S. coelicolor (Hindle and Smith, 1994). The IcIRtype proteins, most often repressors, are characterized by an N-terminally situated helix-turn-helix (DNA binding) domain and a C-terminal substrate binding domain, which is also important for oligomerization of the protein (Zhang et al., 2002). None of the other ssgA-like genes is situated near an iclR-type regulatory gene. The SsgR homologues of S. coelicolor, S. avermitilis and S. griseus (called SsfR) are highly similar, although the $S$. griseus homologue has a predicted $\mathrm{N}$-terminal extension of 84 residues. Insertional inactivation of $s s f R$ in $S$. griseus is phenotypically similar to the $s s g A$ mutant, although $s s g A$ transcription does not depend on SsfR S. griseus (Yamazaki et al., 2003).

In this work, we study the transcriptional regulation of ssgA and ssgR in S. coelicolor A3(2) strain M145 and its early sporulation mutants whiA, whiB, whiG, whiH, whil and whiJ, together with the transcriptional dependence of $s s g A$ on $s s g R$. We identified significant differences in the regulation of $s s g A$ between $S$. coelicolor and $S$. griseus, and propose that this is one of the determinants of the morphological and developmental divergence between the two microorganisms.

\section{Results}

$\mathrm{ssgR}$ is important for sporulation of S. coelicolor

The $s s g R$ gene ( $S$. coelicolor database reference SCO 3925) encodes a 241 amino acid IcIR-type regulatory protein. Fourteen putative iclR-like genes could be identified within the $S$. coelicolor genome. An interesting feature of SsgR is its predicted transmembrane (TM) helix, YALGTVCAAIPITVGTTAATM (residues 185-205; high probability, as predicted by the TMPred server). Orientation is most likely $\mathrm{N}$-terminus inside, which is consistent with the presence of a predicted helix-turn-helix $(\mathrm{HTH})$ DNA binding domain in the $\mathrm{N}$-terminal section of the protein (aa 19-40). Highly similar TM domains are also found in the SsgR homologues from S. avermitilis (SAV4268) and S. griseus (SsfR; AAF61237). Another IcIR-type regulator occurs in $S$. coelicolor with a highly similar putative TM domain (SCO2832, predicted TM sequence YAVGTV CAAVPITAGSAVGCL), which is the closest relative of SsgR in S. coelicolor (40\% overall amino acid identity). However, its HTH domain is very different from that of SsgR.

To study the possible role of $s s g R$ in S. coelicolor M145, an in frame deletion mutant of $S$. coelicolor $s s g R$ was created, as described in the Experimental procedures section. This removed the approximately $280 \mathrm{bp} \mathrm{Ncol-Sphl}$ fragment of $s s g R$, resulting in an in frame deletion of the gene corresponding to aa 78-172. This mutant was designated GSR1. As shown in Figure 1, the mutant had a phenotype similar to that of the ssgA mutant GSA3; similarly, GSR1 formed aerial hyphae, but failed to produce spores on rich media such as R2YE or MM with glucose as the sole carbon source. Spores were produced on particular media, notably on MM with mannitol or on SFM, although at reduced levels and after prolonged incubation (Fig. 1). Such an unusual conditionally White phenotype is also typical of the $s s g A$ mutant (van Wezel et al., 2000a).

\section{$\mathrm{ssgR}$ is transcribed from a single developmentally regulated promoter}

For transcriptional analysis of $s s g R$ and precise localization of the transcriptional start sites, transcript mapping experiments were performed on RNA isolated from $S$. coelicolor M145 grown on MM agar plates with mannitol as the sole carbon source. RNA was isolated at 12-24 h intervals during 5 days, so as to provide representative samples to analyse transcription. The developmental stage of the samples was monitored using phase-contrast microscopy. 


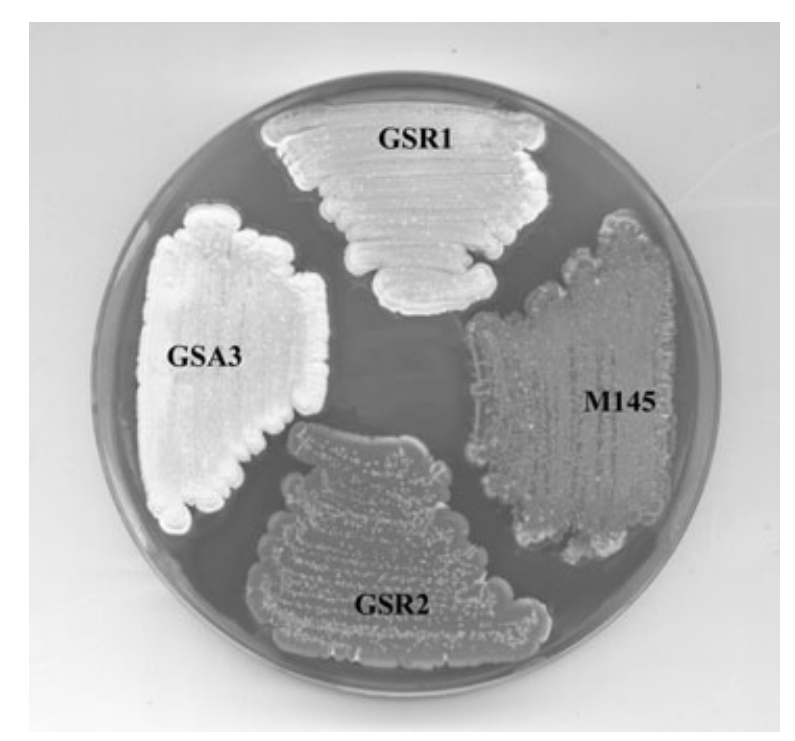

Fig. 1. Phenotypes of the $s s g A$ and $s s g R$ mutants. Sections of the relevant strains were streaked onto SFM plates and photographed after 7 days. Strains used in this experiment: M145, wild-type $S$. coelicolor, GSA3, ssgA::aadA disruption mutant; GSR1, ssgR in frame deletion mutant; GSR2, GSR1 complemented by $s s g R$ (pGWR1). Note the slightly grey appearance of the mutants, indicative of a low degree of sporulation on this particular medium.

Considering the low expression level of $s s g R$ (see below) we used an end-to-end ${ }^{32} \mathrm{P}$-labelled RNA probe for transcript mapping. RNA protection analysis using probe ssgR-T7 (-358/+1, relative to the $s s g R$ translational start; Fig. $2 A$ ) resulted in one major protected band, with a length of approximately $210 \mathrm{nt}$ (Fig. 3). Transcription of $s s g R$ was upregulated after approximately $64 \mathrm{~h}$, corresponding to the onset of sporulation (few spores were observed by phase-contrast microscopy at this point). The experiment was repeated several times, also using RNA derived from cultures grown on SFM instead of MM agar plates. Although the mycelium grew significantly faster on SFM than on MM, the developmental dependence of $s s g R$ transcription was very similar in all experiments (not illustrated). Promoter probing experiments using the redD reporter system (van Wezel et al., 2000c) confirmed the presence of promoter activity immediately upstream of $s s g R$ (data not illustrated), ruling out the possibility that the transcripts had arisen from processing of an upstream-located promoter.

The exact transcriptional start point of the $s s g R$ transcript was identified by co-migration of the protected RNA probe together with a DNA sequencing ladder. The most likely transcriptional start site was identified as one of two A residues around $210 \mathrm{nt}$ upstream of the translational start of $s s g R$ (Fig. 3B). This transcriptional start site is preceded by the sequence TAGAGT, which fully conforms to the consensus -10 sequence (TAGAPUT) for promoters recognized by the major RNA polymerase $\sigma$ factor $\left(\sigma^{\text {hrdB }}\right)$ of Streptomyces (Strohl, 1992). However, we failed to identify a plausible -35 sequence. Transcriptional analysis of the S. griseus ssgR orthologue, designated ssfR, showed that it is also transcribed from a single promoter, with a promoter sequence that is similar to that of $s s g R p$; the -10 sequences are almost identical (TAGAGT for $S$. coelicolor, TACAGT for $S$. griseus) and of the $-50 /-8$ regions (relative to the transcriptional start sites), $62 \%$ of the nucleotides are identical (S. Horinouchi, pers. commun.). Upstream of the $S s g R$ homologue of $S$. avermitilis we identified a sequence that is highly similar to the $s s g R$ promoter of $S$. coelicolor and this sequence therefore constitutes a likely $s s g R$ promoter. This putative promoter (presumed $-50 /-1$ region is $80 \%$ identical to that of $S$. coelicolor ssgRp) would start around nt position -240 relative to the start of $S$. avermitilis ssgR.

\section{Transcription of ssgA is dependent on ssgR}

High-resolution mapping of $s s g A$ transcripts was performed on the same RNA as was used for the analysis of $s s g R$ transcription, with RNA probe ssgA-T7 (-195/+41, relative to the $s s g A$ translational start; Fig. $2 \mathrm{~A}$ and $\mathrm{B}$ ). Two RNA-protected bands of approximately $125 \mathrm{nt}$ and $110 \mathrm{nt}$ were observed ( $\mathrm{p} 1$ and $\mathrm{p} 2$, respectively; Fig. 4A, left panel). The bands appear as double bands, with one nt difference. Such a duplication is often seen, e.g. for the fts Z promoters (Flärdh et al., 2000) and the sigF promoter (Kelemen et al., 1998), probably as the result of an experimental artefact. Whereas in all independent experiments it was difficult to detect $s s g R$-derived transcripts, $s s g A$ transcripts could be readily detected. SsgA transcription was induced after approximately $80 \mathrm{~h}$, a time point where sporulation was well underway, while $s s g R$ transcription was induced one time point earlier, corresponding to the onset of sporulation. Thus, transcription of $s s g R$ is activated at least several hours prior to transcription of $s s g A$. We did not observe full-length protection of the probe in these experiments, which was confirmed by experiments using probe ssgA-S1 in Fig. 5 (below), which carries a 50 nt non-homologous extension at its $3^{\prime}$ end.

Co-migration of a DNA sequencing ladder showed that the transcriptional start sites corresponded to the approximate nt positions -84 and -69 relative to the translational start of $s s g A$, respectively (Fig. 4B). The transcriptional start sites (full sequences in Fig. 2B) are preceded by the sequences $5^{\prime}$-TTGTGA-18 bp-CAAGAT-3' (for p1) and 5' -TTGAGC-15 bp-TTAGAG-3' (for p2), which show limited similarity to the consensus -35 and -10 sequences (5'-TTGACN-16-18 bp-TAGAPUT-3'; (Strohl, 1992) for promoters recognized by the major RNA polymerase holoenzyme of Streptomyces.

Because $s s g R$ and $s s g A$ mutants are phenotypically highly similar, a possible dependence of $s s g A$ transcrip- 
A

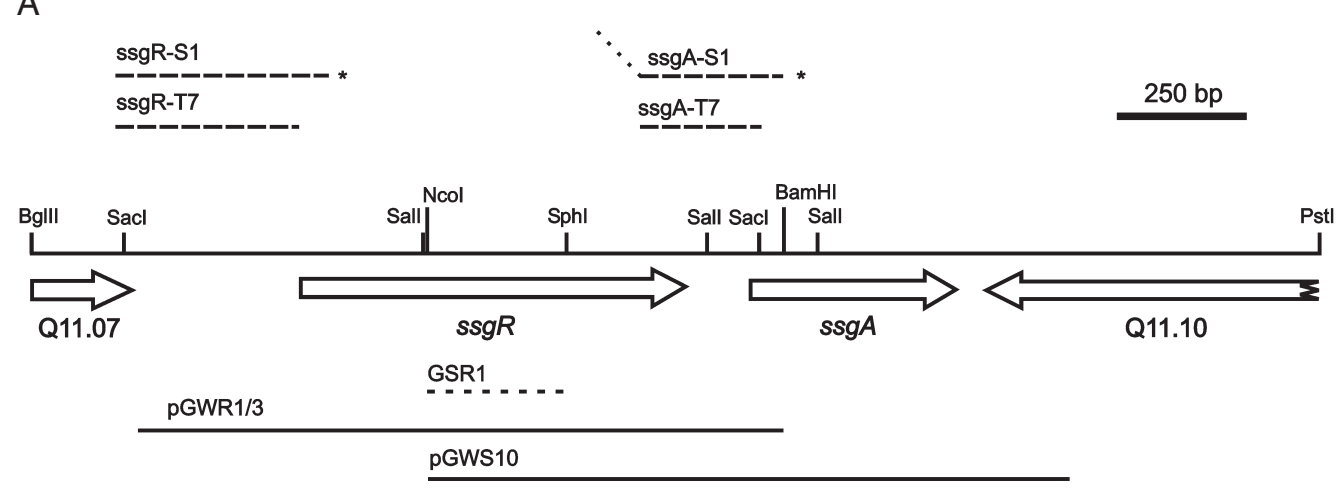

B

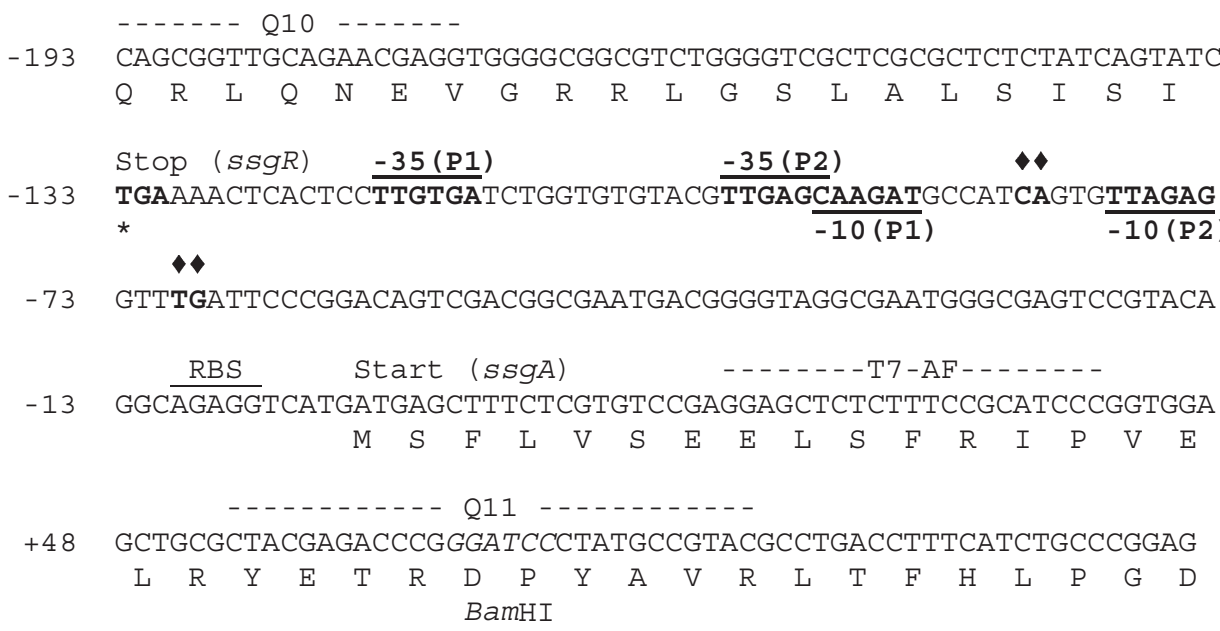

Fig. 2. Map of the ssgRA gene cluster and sequence of the $s s g A$ promoter region.

A. Map of $s s g R A$ and location of DNA fragments and probes. The ssgRA gene cluster is located on cosmid Q11. The most likely translational start of ssgR (ORF Q11.8; accession CAB46964) is a GTG triplet at nt position 4318648 on the genome, that of $s s g A$ (Q11.9; accession CAB46963) an ATG triplet at nt position 4319504, resulting in proteins of 241 amino acids (SsgR) and 135 aa (SsgA) respectively. ORFs shown as arrows, indicating the direction of their transcription. Inserts of complementation constructs are shown by solid lines below the map. Dashed lines above the map represent the location of probes used for high resolution transcript mapping (See Experimental procedures, section 'transcript mapping and probes'). Extension (tilted dotted line) indicates $50 \mathrm{nt}$ stretch containing non-homologous vector sequences. The approximately $280 \mathrm{nt}$ deletion in the $s s g R$ mutant GSR1 is represented by a dashed line below the sequence.

B. DNA sequence of the $s s g R A$ intergenic region. Nucleotide numbering refers to the $s s g A$ translational start site. $\bullet$, transcriptional start sites (see Fig. 4B); putative -35 and -10 sequences are overlined and underlined respectively. Derived aa sequences corresponding to the end of $s s g R$ and the start of $s s g A$ are shown below the sequence. RBS, putative ribosome binding site. $\mathrm{p} 1$ and $\mathrm{p} 2$ refer to transcription start sites observed in surface-grown cultures. Important oligonucleotides are indicated (T7-AF and Q11 are complementary to the coding strand).

tion on SsgR was investigated. For this purpose, transcriptional analysis was performed using RNA isolated from surface-grown MM mannitol cultures of GSR1, the congenic ssgR mutant of $S$. coelicolor M145. We repeatedly failed to detect significant levels of $s s g A$ transcripts in these samples, suggesting that $s s g A$ transcription is directly or indirectly dependent on SsgR in S. coelicolor (Fig. 4A, right panel). The integrity of the RNA was confirmed by mapping the transcript of $s s g D$ (SCO6722), one of the six ssgA-like genes in $S$. coelicolor, using the same RNA as in the experiments for mapping $s s g A$ transcripts. The $s s g D$ gene is expressed in all growth phases and in an $s s g R$-independent manner, from a single promoter (B. Traag and G. P. van Wezel, unpublished data). We observed no difference between M145 and GSR1 (data not illustrated). The absence of ssgA-derived transcripts in the $s s g R$ mutant was confirmed by RT-PCR experiments (see below).

\section{Expression of SsgA restores sporulation to an ssgR mutant}

To further assess the dependence of $s s g A$ transcription on $s s g R$, we analysed the morphological effect of $s s g R$-independent expression of $s s g A$ in the $s s g R$ mutant. For this purpose, two constructs were introduced into GSR1, one with ssgA preceded by its own (putatively SsgR-dependent) regulatory sequences and 
A

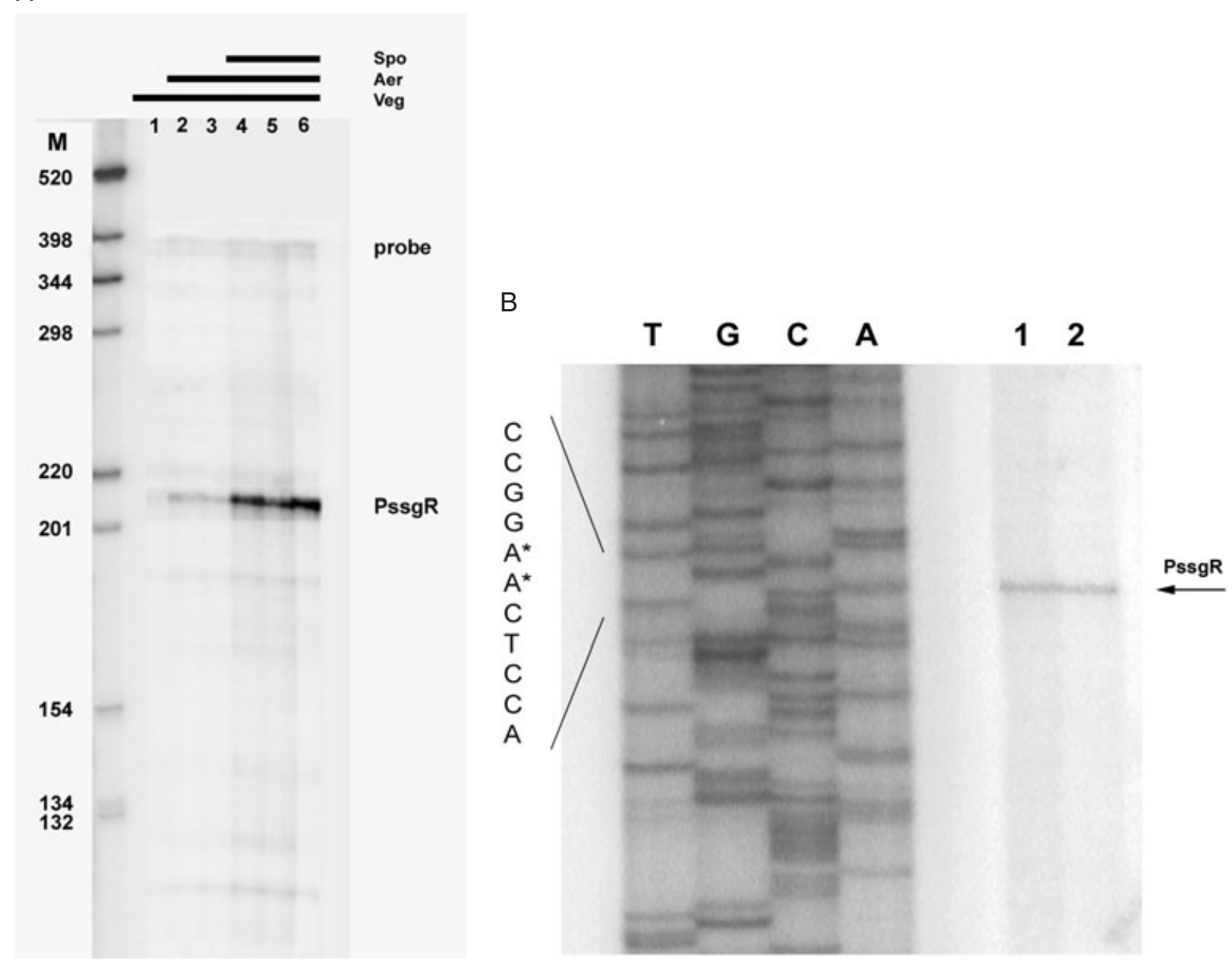

Fig. 3. Growth phase-dependent transcription of S. coelicolor ssgR.

A. Transcript mapping experiment to identify ssgR transcripts. RNA was isolated from solid-grown MM + mannitol cultures of $S$. coelicolor M145, and analysed using high resolution transcription analysis. RNA time points: (1) 24 h; (2) 36 h; (3) 48 h; (4) 64 h; (5) 80 h; (6) 96 h. Sample 2 corresponded to the onset of aerial mycelium formation and sporulation started after approximately $64 \mathrm{~h}$ (sample 4). The RNA probe used for the RNA protection assays was ssgR-T7 (Fig. 2A). While $s s g R$ transcripts were already visible in samples 2 and 3 , transcription of $s s g R$ was strongly enhanced as soon as sporulation started. The location and developmental regulation of the $s s g R$ promoter was verified with different probes and independent experiments (e.g. Fig. 5B)

B. Determination of the exact transcription start site of $s s g R$. TGCA, $s s g R$ nucleotide sequence ladder. Lanes 1 and 2 are the same samples as shown in lanes 2 and 3 in Fig. 3A. Asterisks indicate the most likely transcriptional start site, coinciding with two A residues at nt positions -210 and -211 , relative to the $s s g R$ translational start site respectively.

one with SsgA positioned behind the SsgR-independent and constitutive ermE promoter. In a control experiment, we also introduced $s s g R$ expression constructs in the ssgA mutant. In the latter case, no effect was expected. As additional controls, $s s g R$ and $s s g A$ mutants were complemented by wild-type copies of $s s g R$ and $s s g A$ respectively. The results are shown in Fig. 6A.

As was anticipated, the $s s g A$ and $s s g R$ mutants could be complemented by the introduction of wild-type ssgA (on pGWS10, giving transformant GSA4) and $s s g R$ (on pGWR1, transformant GSR2) respectively. This underlines that the non-sporulating phenotype of the $s s g R$ and
ssgA mutants is solely the result of the respective gene deletions. Interestingly, morphological differentiation of the $s s g R$ mutant could be fully restored by the expression of $s s g A$ under the control of the SsgR-independent ermE promoter (GSR4 in Fig. 6A). Therefore, the sporulation deficiency of the $s s g R$ mutant is due to the lack of sufficient SsgA. In contrast, introduction of multiple copies of $s s g A$ behind its own promoter did not complement the $s s g R$ mutant (GSR3 in Fig. 6A), providing additional evidence that the natural $s s g A$ promoters are both inactive in an $s s g R$ mutant background. Finally, as expected, introduction of pGWR1 in the ssgA mutant (transformant GSA5) had no apparent effect on development. As a con- 
A

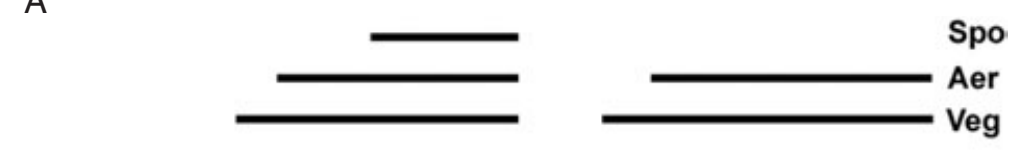

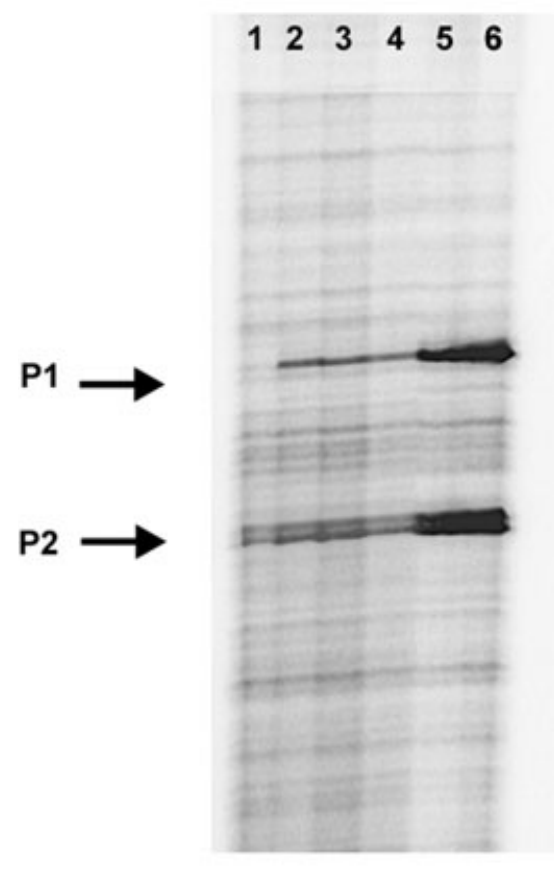

M145

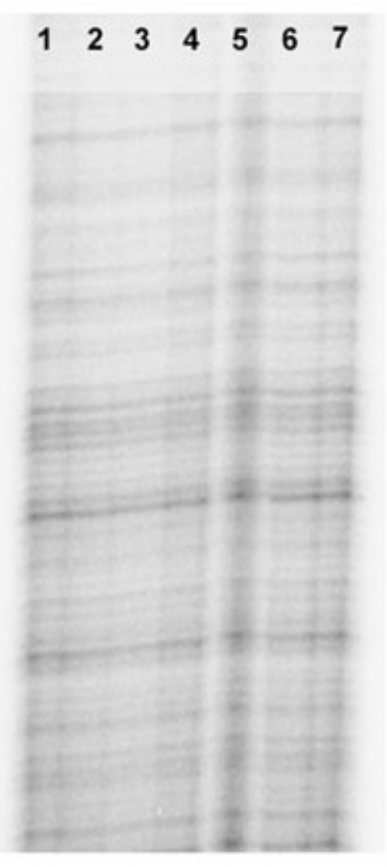

$\Delta s s g R$
B

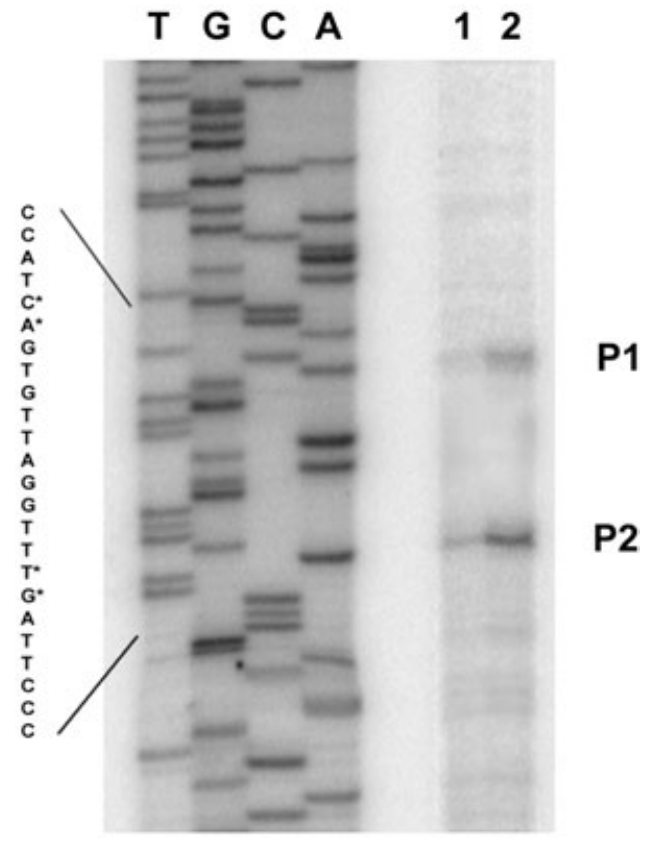

C

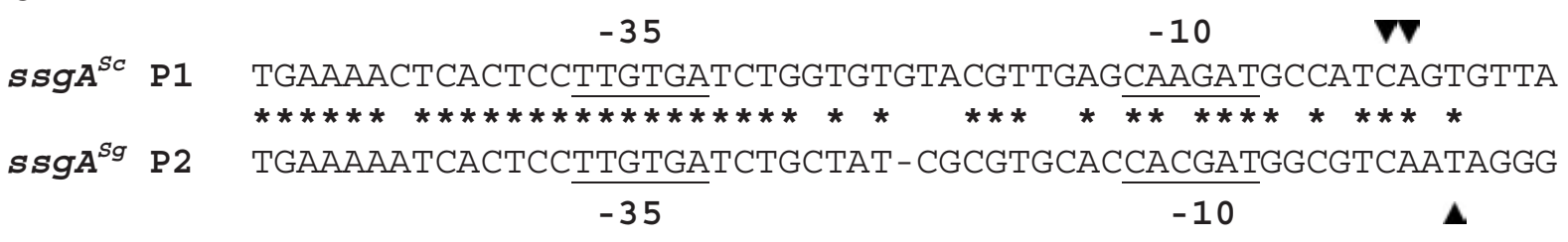

Fig. 4. Growth phase-dependent transcription of $S$. coelicolor $s s g A$ and dependence on $s s g R$.

A. Transcript mapping experiment to identify ssgA transcripts in S. coelicolor M145 and its congenic ssgR mutant GSR1. RNA was isolated from solid-grown MM cultures. The RNA probe used for the RNA protection assays was ssgA-T7 (Fig. 2A). Left panel: transcription in M145. The RNA used was the same as in Fig. 3. Bands $\mathrm{p} 1$ and P2 correspond to ssgA transcripts. The intensity of both transcripts varied in a growth phasedependent manner, with a maximum in lane 5 (80 h). Right panel: transcription in GSR1. RNA time points: (1) 24 h; (2) 36 h; (3) 48 h; (4) 64 h; (5) $80 \mathrm{~h}$; (6) $96 \mathrm{~h}$; (7) $120 \mathrm{~h}$. Sample 3 corresponded to the onset of aerial mycelium formation. The relatively strong background is due to the use of a T7-generated RNA probe with incorporated nucleotides. The location and developmental regulation of the promoters was verified with several different probes and independent experiments (e.g. S1 mapping, Fig. 5).

B. Determination of the transcription start sites of $s s g$. TGCA, ssgA nucleotide sequence ladder. Lanes 1 and 2 correspond to the same samples as shown in lanes 2 and 3 in Fig. 4A. Asterisks indicate the most likely transciptional start sites for the two transcripts, coinciding with a $C$ residue (for $\mathrm{p} 1$ ) and a $\mathrm{G}$ residue (for $\mathrm{p} 2$ ), at nt positions -84 and -69 , relative to the $s s g A$ translational start site respectively.

C. Alignment of the S. coelicolor ssgA p1 and S. griseus $s s g A$ p2 promoters. Putative -10 sequences underlined; arrowheads indicate the likely transcriptional start site. Asterisks indicate identical nucleotides between the two promoters. Streptomyces griseus ssgA p2 start site taken from (Yamazaki et al., 2003).

trol, all plasmids were transformed to the parental strain M145; these transformants showed normal sporulation, indicating that none of the plasmids had a negative effect on sporulation.

To test if $S$. griseus ssfR could also restore sporulation to the ssgR mutant, we introduced pGWR5 into
GSR1. pGWR5 is essentially the same plasmid as pGWR1, except that it contains ssfR from $S$. griseus B2682 instead of $s s g R$. The non-sporulating phenotype of the resulting transformants shows that introduction of $s s f R$ fails to complement the $S$. coelicolor ssgR mutant (Fig. 6B). 
A
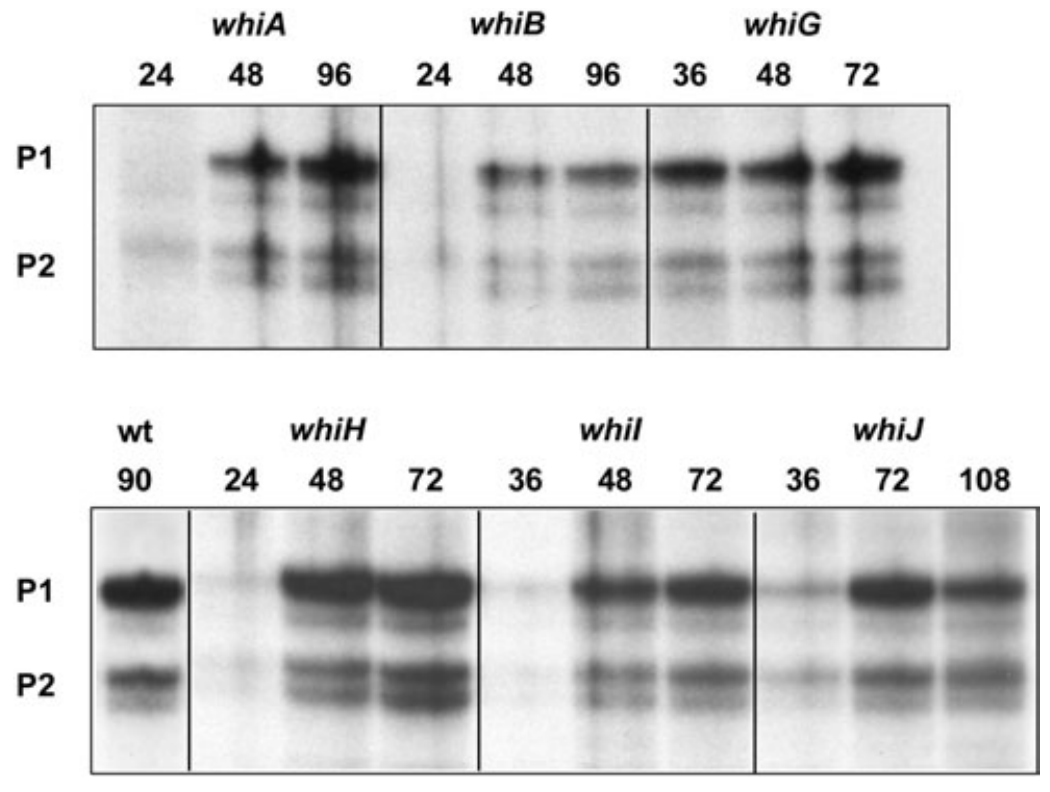

Fig. 5. Transcriptional analysis of $s s g A$ and $s s g R$ in whi mutants of $S$. coelicolor. RNA was isolated from surface-grown MM/Mannitol cultures of the $S$. coelicolor sporulation mutants whiA, whiB, whiG, whiH, whil and whiJ and analysed by nuclease S1 mapping. For each mutant, the first time point corresponds to the transition from vegetative to aerial growth and the second and third time point to aerial growth. A. Transcript analysis of $s s g A$.

B. Transcript analysis of $s s g R$. The probes used were ssgR-S1 and ssgA-S1, respectively (Fig. 2A). As a control we used wild-type $S$. coelicolor $\mathrm{A} 3(2)$, as this is the congenic parent of the whi mutants described in the paper. The results were essentially the same as those shown in Figs 3 and 4 (data not illustrated).

B
wt
whiA
whiB
whiG
90
24
4896
$\begin{array}{lll}24 & 48 & 96\end{array}$
36
48
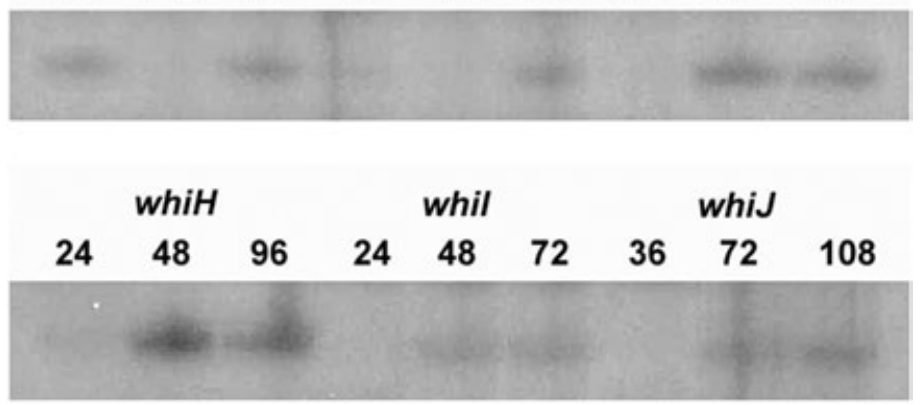

SsgR binds directly and specifically to the ssgA promoter region

To analyse if SsgR could directly bind to the upstream region of $s s g A$, expression constructs were made to express and purify sufficient quantities of the protein for DNA binding assays (Experimental procedures). Construct pGWR11 was designed to produce full-length SsgR (241 aa, called SsgR-241) in E. coli, containing an Nterminal $\mathrm{His}_{6}$-tag for purification using Ni-NTA chromatography. However, the protein was fully insoluble and, after purification of the protein from inclusion bodies using denaturing procedures, renaturation resulted in complete precipitation of the protein with no detectable soluble protein (as judged by SDS-PAGE). The TMPred program identified a likely transmembrane (TM) region in SsgR, encompassing amino acids 185-205 (also present in the homologues of $S$. avermitilis and $S$. griseus). To remove the putative TM domain from the protein, we designed construct pGWR12 to express a shortened SsgR protein (155 aa, called SsgR-155). This resulted in soluble protein, which eluted from a Ni-NTA column in buffer containing $150 \mathrm{mM}$ imidazole.

The protein fraction containing pure SsgR-155 was tested for DNA binding activity in a mobility shift assay. Binding was observed to the DNA fragment SsgA-S1, which contains the $-195 /+45$ section relative to the start of $s s g A$ (Fig. 2A and $\mathrm{B}$ ), producing a single and discrete DNA-protein complex (band $\mathrm{C}$ in Fig. 7). Complete binding (lane 2) was observed with around 25 ng (approximately 1 pmol) of purified protein; at a $1: 12$ dilution (lane 4) virtually all DNA was in the unbound state, although some residual binding activity could be observed. The mobility shift could be fully reversed by the addition of excess of cold probe (Fig. 7, lane 5), whereas the presence of a large excess of pBR322 did not affect binding. A fragment containing a shorter part of the $s s g A$ promoter region (up to -75 relative to the start of $s s g A$ ) bound $S s g R$ 
A

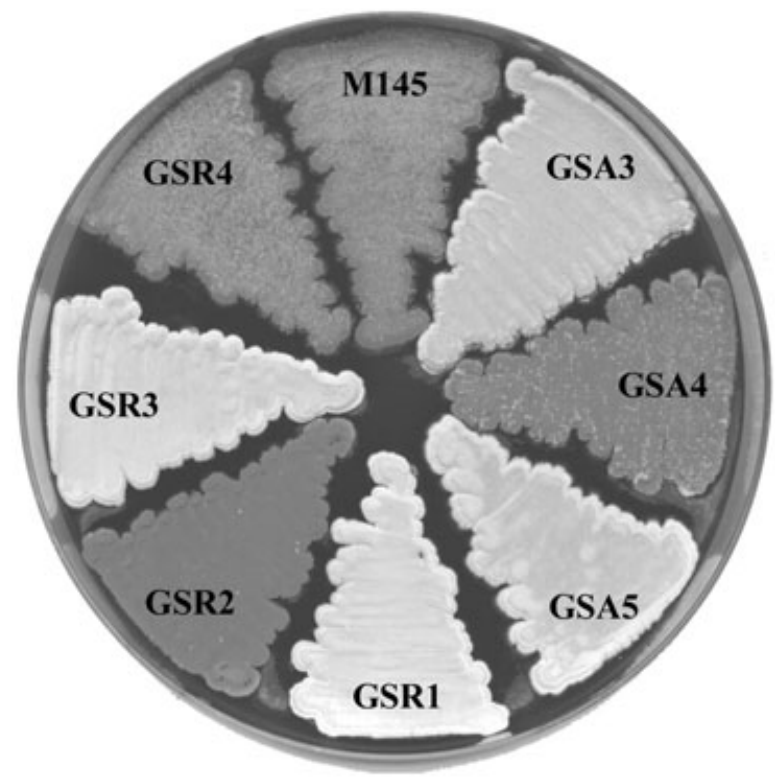

B

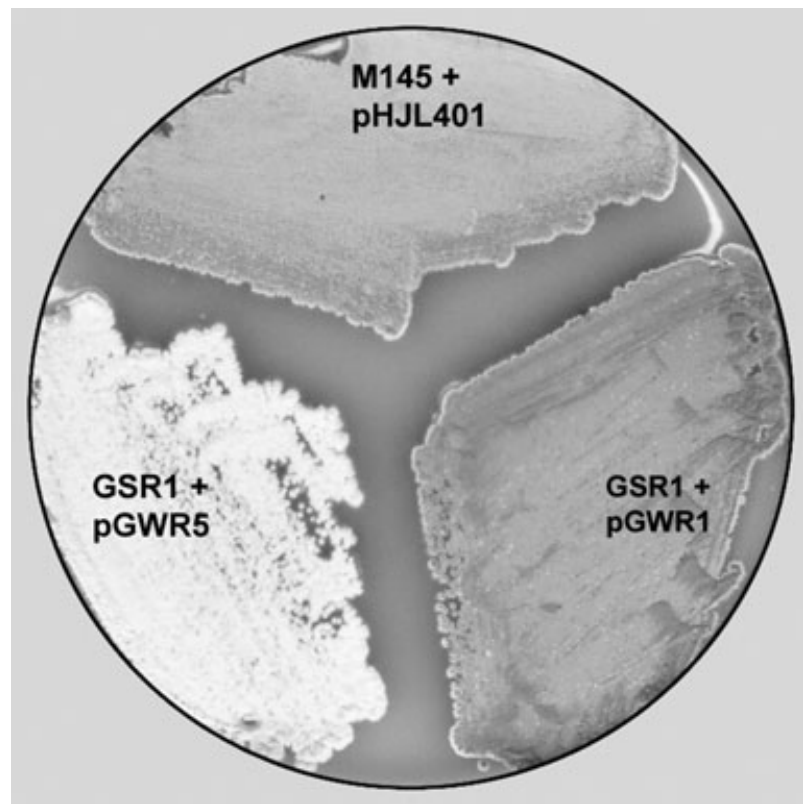

with similar affinity, narrowing down the SsgR binding site to the region between -195 and -75 relative to the start of $s s g A$. Specificity of SsgR for the $s s g A$ promoter was underlined by its failure to bind to the SsgR promoter or to DNA fragments harbouring the start and middle part of the ssgR gene (not shown).

\section{Transcription of SsgA and ssgR in sporulation (whi)} mutants of $\mathrm{S}$. coelicolor

As $s s g A$ controls the formation of sporulation septa and expression of both $s s g A$ and $s s g R$ is induced during
Fig. 6. Complementation of the S. coelicolor ssgR mutant.

A. Complementation of the sporulation-defective phenotypes of the S. coelicolor $s s g A$ and $s s g R$ mutants. Strains used in this experiment: M145, Wild-type S. coelicolor, GSA3, ssgA disruption mutant; GSA4, ssgA mutant complemented by pGWS7; GSA5, ssgA mutant harbouring pGWR1; GSR1, ssgR in frame deletion mutant; GSR2, GSR1 complemented by ssgR (pGWR1); GSR3, GSR1 harbouring pGWS10 (ssgA with its own promoter); GSR4, GSR1 complemented by $s s g A$ expressed from the SsgR-independent ermE promoter (pGWS7). Note that $s s g A$ can only restore sporulation to the $s s g R$ mutant if it is expressed from a promoter that is independent of intact SsgR.

B. Complementation experiment using S. griseus ssfR. Transformants of GSR1 (the ssgR mutant of S. coelicolor M145) with pGWR5 (containing $S$. griseus $s s f R$ ) are shown, which fail to sporulate. Controls are full complementation of GSR1 by pGWR1 and wild-type level of sporulation by $S$. coelicolor M145 harbouring control plasmid pHJL401.

For both experiments, strains were grown on SFM and incubated at $30^{\circ} \mathrm{C}$ for 7 days.

sporulation, a possible dependence of their transcription on the S. coelicolor sporulation genes whiA, whiB, whiG, whiH, whil and whiJ was investigated. RNA from the corresponding whi mutants (Table 1 ) grown on MM agar plates with mannitol as the sole carbon source, was analysed by $S 1$ nuclease mapping. Transcription of $h r d B$, which encodes the principal, essential $\sigma$ factor of $S$. coelicolor, is expressed at a relatively constant level in $S$. coelicolor and was monitored as an internal control (data shown in Kelemen et al., 1998).

S1 nuclease mapping of transcripts with DNA probe ssgA-S1 (-195/+82; Fig. 2A and B) revealed both ssgA transcripts in all whi mutants, showing that none of these genes is essential for $s s g A$ transcription (Fig. 5A). Expectedly, transcripts were absent in RNA isolated from vege-

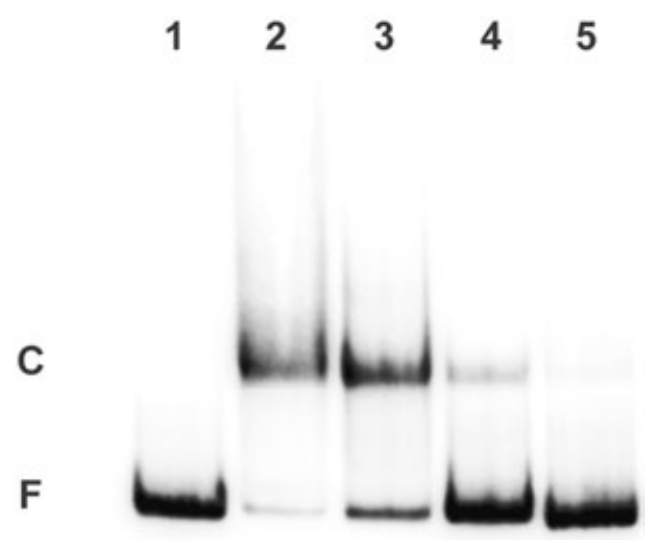

Fig. 7. Binding of SsgR to the $s s g A$ promoter region. Mobility shift assay showing binding of truncated $\mathrm{His}_{6}$-tagged SsgR-155 to the $s s g A$ upstream region $(-195 /+41$ relative tot the start of $s s g A)$. The DNA fragment used was ${ }^{32} \mathrm{P}$-end-labelled ssgA-S1 (Fig. 2A). Lanes: (1) control (no protein); (2) 25 ng SsgR-155; (3) 6 ng SsgR-155; (4) 2 ng SsgR-155; (5) same as lane 3, but with 5-fold excess of cold probe. F, free (unbound) fragment; C, complex of DNA and purified $\mathrm{His}_{6}$-tagged SsgR-155. Similar results were obtained when a smaller probe was used, which encompassed the $-195 /-75$ region relative to the $\operatorname{ssg} A$ translational start site. 
Table 1. Bacterial strains.

\begin{tabular}{|c|c|c|}
\hline Bacterial strain & Genotype & Reference \\
\hline S. coelicolor A3(2) & $\mathrm{SCP}^{+} \mathrm{SCP}^{+}$ & Kieser et al. (2000) \\
\hline S. coelicolor M145 & $\mathrm{SCP}^{-}, \mathrm{SCP}_{2}^{-}$ & Kieser et al. (2000) \\
\hline M851 & adpA $(b / d H)$ mutant of $\mathrm{M} 145$ & Takano et al. (2003) \\
\hline C72 & whiA71 pgl ${ }^{+} \mathrm{SCP}^{+} \mathrm{SCP}^{+}$ & Chater (1972) \\
\hline $\mathrm{C} 70$ & whIB70 $\mathrm{pgl}^{+} \mathrm{SCP} 1^{+} \mathrm{SCP}^{+}$ & Chater (1972) \\
\hline C71 & whiG71 pgl SCP1 $^{+} \mathrm{SCP}^{+}$ & Chater (1972) \\
\hline C119 & whiH119 $\mathrm{pgl}^{+} \mathrm{SCP}^{+} \mathrm{SCP}^{+}$ & Chater (1972) \\
\hline C17 & whil17 $\mathrm{pgl}^{+} \mathrm{SCP} 1^{+} \mathrm{SCP}^{+}$ & Chater (1972) \\
\hline C77 & whis77 pgl+ $\mathrm{SCP}^{+} \mathrm{SCP}^{+}$ & Ryding (1998). \\
\hline GSA3 & M145 $\Delta s s g A(:: a a d A)$ & van Wezel et al. (2000a) \\
\hline GSA4 & M145 $\Delta s s g A+$ pGWS7 & van Wezel et al. (2000a) \\
\hline GSA5 & M145 $\Delta s s g A+$ pGWR1 & van Wezel et al. (2000a) \\
\hline GSR1 & M145 $\Delta s s g R$ & This paper \\
\hline GSR2 & M145 $\Delta s s g R+$ pGWR1 & This paper \\
\hline GSR3 & M145 $\Delta s s g R+$ pGWS10 & This paper \\
\hline GSR4 & M145 $\Delta s s g R+$ pGWS7 & This paper \\
\hline E. coli JM109 & See reference & Sambrook et al. (1989) \\
\hline E. coli ET12567 & See reference & MacNeil et al. (1992) \\
\hline
\end{tabular}

tative mycelium. Developmental regulation of $s s g A$ was also not significantly affected in any of the whi mutants, although $s s g A$ transcription was slightly but reproducibly upregulated in the whiH mutant, which is developmentally stalled in a phase immediately before the onset of sporulation-specific cell division (Ryding et al., 1998).

Transcriptional analysis of $s s g R$ in the whi mutants was done with DNA probe ssgR-S1, encompassing the -338/ +47 region relative to the $s s g R$ translational start site (Fig. 2A). Similar to $s s g A, s s g R$ appeared slightly upregulated in the whiH mutant, but was otherwise not significantly affected in any of the whi mutants (Fig. 5B).

\section{RT-PCR analyses of developmental genes}

In an independent set of experiments, we performed transcript analysis on RNA isolated from surface-grown MM Mannitol cultures by RT-PCR (Fig. 8). To establish whether $s s g R$ is important for earlier stages of aerial development, we analysed the transcription of the crucial regulatory gene whiG. The outcome of was very similar for M145 and the ssgR mutant, with approximately constant transcript levels of whiG relative to the 16S rRNA in both strains, showing that whiG transcription was not significantly affected by the deletion of $s s g R$ (Fig. 8). Expectedly, there was a strong increase in $s s g A$ transcript levels in RNA samples from surface-grown M145 towards the onset of sporulation (48 and $96 \mathrm{~h}$ ), while we failed to detect $s s g A$-derived transcripts in the $s s g R$ mutant. These results correspond well to the transcript mapping experiments presented in Fig. 4A. Considering the dependence of $s s g A$ on $\operatorname{adpA}(b / d H)$ in $S$. griseus, we also analysed $s s g A$ transcription in adpA mutant M851, which was characterized previously (Takano et al., 2003). Interestingly, ssgA-derived transcripts were readily detected in this mutant; however, presence of $s s g A$ transcripts in the $24 \mathrm{~h}$ sample (corresponding to vegetative growth) indicates that its regulation may be affected in the adpA mutant.

\section{Discussion}

$\mathrm{ssgR}$ and ssgA are transcribed in a growth-phase dependent manner

Our results show that $s s g A$ and $s s g R$ are sporulation genes, transcribed in a growth phase-dependent manner on solid-grown cultures. A constructed ssgR mutant had a phenotype very similar to that of the $s s g A$ mutant published previously (van Wezel et al., 2000a), showing a conditional White phenotype (no sporulation except on mannitol-containing media). The $s s g R$ gene was tran-

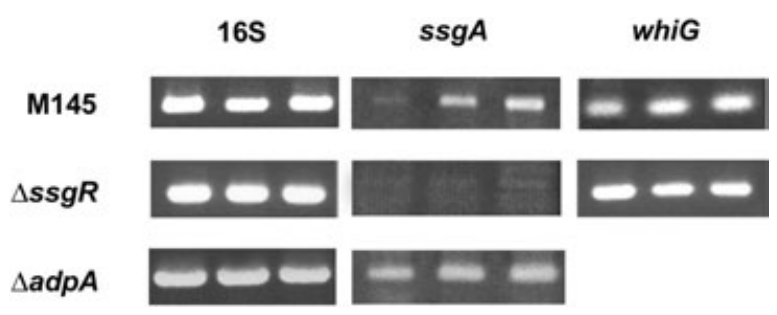

Fig. 8. Transcriptional analysis of developmental genes by RT PCR. Time points were (from left to right) $24 \mathrm{~h}, 48 \mathrm{~h}$ and $96 \mathrm{~h}$, corresponding to vegetative growth, aerial growth and sporulation, respectively, for all three strains. Strains (vertical axis) were: S. coelicolor M145 and its $s s g R$ and adpA mutant derivatives (GSR1 and M851, respectively). RNA was obtained from mycelium grown at $30^{\circ} \mathrm{C}$ on SFM plates (using a cellophane overlay). RNA (transcripts) analysed in the mutants are shown on horizontal axis (16S rRNA ("16S'), ssgA and whiG). The RT-PCR experiments revealed normal whiG transcription in the $s s g R$ mutant and dependence of $s s g A$ transcription on $s s g R$, but not on adpA. whiG transcription was not analysed in the adpA mutant. SFM agar plates were used to allow sporulation of the $s s g R$ and $\operatorname{adp} A$ mutants. 
scribed from a single growth phase-dependent promoter (ssgRp) in solid-grown cultures of $S$. coelicolor M145. Whereas steady-state transcript levels of $s s g R$ were low under the conditions tested, the activation of $s s g R p$ coincided with the onset of aerial mycelium formation and transcript levels were strongly upregulated at the onset of sporulation. A very similar promoter was responsible for transcription of the $s s g R$ orthologue in S. griseus (S. Horinouchi, pers. commun.). The sequence TAGAGT separated by $5-6$ nt from the transcriptional start site, constitutes a -10 promoter consensus sequence that may be recognized by the principal sigma factor $\sigma^{\text {hrdB }}$, but a -35 consensus sequence for this probable promoter could not be identified.

$\operatorname{ssg} A$ is transcribed from two promoters ( $s g g A$ p1 and $s s g A$ p2), separated by approximately $15 \mathrm{nt}$, suggesting overlap between them. The absence of read-through indicates that on solid-grown cultures, $s s g A$ is transcribed only from these two promoters. Earlier experiments with liquid-grown cultures showed that $s s g A$ is expressed at a low level and only after nutritional downshift and co-regulated with $s s g R$ from a full-length transcript (van Wezel et al., 2000a). This experiment was repeated, again showing read-through from the $s s g R$ promoter (data not illustrated). This discrepancy remains unexplained, but could reflect interesting differences between liquid- and solidgrown cultures. Both promoters were developmentally controlled and maximal transcript levels were reached one time point later than those of $s s g R$ transcripts, at a time corresponding to sporulation. Such a sporulation-specific expression conforms to a role in the activation of sporulation-specific cell division. Despite the similar developmental regulation and strength of $s s g A \mathrm{p} 1$ and $\mathrm{p} 2$, there is no obvious similarity between the respective promoter sequences.

Comparison to the $S$. griseus ssgA promoters revealed almost complete conservation between $s s g A^{s c} \mathrm{p} 1$ and $s s g A^{s g}$ p2 (Fig. 4C). This sequence is also highly conserved in $S$. avermitilis. However, $s s g A^{S c}$ p2 shows no sequence similarity to $s s g A^{S g} \mathrm{p} 1$. Apparently, some elements of $s s g A$ regulation are shared between $S$. coelicolor and $S$. griseus, whereas others are different (see the final paragraph).

\section{Expression of ssgA is activated by $\mathrm{SsgR}$}

Our failure to detect $s s g A$ transcripts in the $s s g R$ mutant indicated that the growth-phase-dependent induction of $s s g A$ transcription is dependent on SsgR. This is in accordance with the observation that $s s g R$ transcription is strongly induced one time point earlier than that of $s s g A$, at a time between aerial hyphae formation and the onset of sporulation; transcripts of $s s g A$ itself were induced when sporulation was initiated. Interestingly, $s s g A$ tran- scripts were more abundant than those of $s s g R$, as seen in multiple independent experiments. In further support of activation of $s s g A$ transcription by $\mathrm{SsgR}$, introduction of a plasmid expressing $s s g A$ from the constitutive and SsgRindependent ermE promoter restored a wild-type phenotype to the $s s g R$ mutant of $S$. coelicolor, whereas a similar plasmid harbouring $s s g A$ with its natural promoter failed to complement the mutant. This suggests that whereas it is possible that other genes are regulated by $s s g R$, the sporulation deficiency of the $s s g R$ mutant is solely due to lack of SsgA and that $s s g A$ transcription fully depends on SsgR. This is also supported by the observation that fragmentation of $S$. coelicolor in submerged culture, typical of transformants expressing $s s g A$, was induced by the introduction of pGWR3, a multicopy plasmid harbouring only $s s g R$ (data not illustrated). Interestingly, introduction of a plasmid harbouring $S$. griseus ssfR did not restore sporulation to the $s s g R$ mutant, indicating significant functional differences between the respective gene products. SsgR of $S$. coelicolor belongs to the family of IcIR-like transcriptional regulators (Zhang et al., 2002). These proteins are characterized by an N-terminal DNA binding domain and a C-terminal ligand binding domain, which is also important for oligomerization of the protein. Typically, binding of the substrate induces a conformational change, releasing the protein from its target sequence (Zhang et al., 2002; Yamamoto and Ishihama, 2003). As an exception, the Streptomyces SsgR/SsfR proteins have a predicted transmembrane helix. Our experiments suggest that cleavage of this putative TM domain is required for its solubility, as only a truncated version of SsgR (155 amino acids long) was soluble. Whether SsgR also binds a substrate is unclear, but considering that on several occasions it was shown that the C-terminal section of IcIR-type proteins is required for interaction between monomers, its removal is expected to affect the mode of binding of SsgR. The truncated SsgR155 produced a single mobility shift on a DNA fragment containing the ssgA promoter region, indicating that the SsgR dependence of the transcription of $s s g A$ is mediated through direct trans-activation by SsgR. The binding site was narrowed down to the $-195 /-75$ section relative to the $\operatorname{ssg} A$ gene. The region around the stop codon of $s s g R$ constitutes a possible binding site, as it harbours a for streptomycetes unusually $A / T$-rich sequence (TGAAAACTCACTCC) that shows significant similarity to the consensus sequence TGAAAA(A/T)NNTTTPyPy for IclR-type binding sites (Pan et al., 1996; Zhang et al., 2002). Typically, IcIR-type regulators bind to multiple IcIR boxes, although we failed to observe additional binding by SsgR. We cannot rule out the possibility that this different behaviour results from the absence of the C-terminal (interaction) part of the protein, which we had to remove to obtain soluble SsgR protein. We are currently analys- 
ing the mode of action and the activation of SsgR in more detail.

\section{Interdependence of ssgRA and other developmental genes}

In S. coelicolor whiA, whiB, whiG, whil and whiJ mutants, the level and timing of $s s g A$ and $s s g R$ transcription are comparable to those found in the parental wild-type $S$. coelicolor A3(2) as well as those in S. coelicolor M145. Considering that $s s g R A$ transcripts are found in all 'early' whi mutants analysed, this strongly suggests that the gene cluster is not controlled by the classical whi genes. In a reverse experiment, we also showed that whiG is not significantly affected in an $s s g R$ mutant, providing further support for the mutual independence of the ssgRA cluster on the one hand, and the early whi genes on the other. This independence is apparently supported by the observation that the White phenotype of the $s s g A$ and $s s g R$ mutants is medium-dependent and that these genes as well as most of the $s s g A$-like genes are under carbon catabolite control, which is not the case for other whi genes (manuscript in preparation). Further transcriptional analysis is required to assess whether the observed upregulation of whiH in the $s s g A$ and $s s g R$ mutants is significant. A possible explanation for the necessity of whi gene-independent expression of $s s g R A$ is that the genes are also involved in the activation of sporulation-specific cell division under conditions where an aerial mycelium is not produced, in particular during submerged sporulation. Indeed, ssgA is essential for this process in $S$. griseus (Kawamoto et al.,1997) and its overexpression results in hyperseptation and a low level of submerged sporulation in S. coelicolor (van Wezel et al., 2000a).

\section{Differential regulation of SsgRA in S. coelicolor and S. griseus}

How does the situation in S. coelicolor compare to that in S. griseus? In the latter organism, ssgA is dependent on AdpA, an A-factor-dependent transcriptional activator that is essential for development and streptomycin production (Ohnishi et al., 2002). In contrast, S. coelicolor scbA mutants fail to produce the A-factor-like $\gamma$-butyrolactone SCB1, but show normal sporulation (Takano et al., 2001) and $\operatorname{adpA}$ mutants sporulate normally on mannitol-containing media (Takano et al., 2003). As such sporulation is not possible in the absence of $s s g A$, its transcription is most probably not dependent on SCB1 or AdpA, which was confirmed by our observation that $s s g A$ transcripts could be readily detected in an $S$. coelicolor adpA mutant. Rather, in $S$. coelicolor both $s s g A$ promoters are directly dependent on activation by SsgR. Whereas in $S$. griseus the activity of $s s g A^{S g}$ p2 (virtually identical to $s s g A^{S c} \mathrm{p} 1$,
Fig. 4C) also depends on SsfR, that of $s s g A^{S g} \mathrm{p} 1$ does not, which results in significant expression of $s s g A$ in an ssfR mutant (Yamazaki et al., 2003). Therefore, regulation is clearly different in $S$. griseus, also illustrated by the significantly higher $s s g A$ transcript levels in this organism, which is a prerequisite for submerged sporulation (G. P. van Wezel, unpublished data).

In summary, several important differences exist between the regulation of the $s s g A$ orthologues in $S$. coelicolor [indicated with $\left({ }^{S c}\right)$ ] and that in S. griseus $\left({ }^{S g}\right)$ :

i $s s g A^{S c}$ fully depends on activation by SsgR, whereas activity of only one of the $s s g A^{S g}$ promoters is reduced in an ssfR mutant.

ii The $S s g R^{S c}$ and $S s f R^{S g}$ proteins may be functionally different, as the gene from $S$. griseus fails to complement the $S$. coelicolor ssgR mutant.

iii It is unlikely that the A-factor-like molecule SCB1 plays a role in the regulation of $s s g A^{S c}$, whereas A-factor is essential for the regulation of $s s g A^{S g}$ (through AdpA). This may at least partially explain the different impact of A-factor on the development of these organisms, because SCB1 (and on mannitol also AdpA) mutants of $S$. coelicolor sporulate normally, whereas A-factor is essential for sporulation of $S$. griseus (Takano et al., 2001).

iv There is no detectable transcription of $s s g A^{S c}$ in submerged culture under normal conditions, while it is strongly expressed in $S$. griseus (Kawamoto et al., 1997; van Wezel et al., 2000a;b).

The expression level of $s s g A$ has a major impact on mycelial morphology of both organisms (Kawamoto et al., 1997; van Wezel et al., 2000a,b) and the different expression levels of $s s g A$ in these organisms thus provides a possible explanation for their strong morphological differences in submerged cultures, and this may be one of the main reasons why $S$. griseus is able to sporulate in submerged culture but not $S$. coelicolor.

We are currently investigating the exact roles of SsgA and SsgR in the sporulation process, with focus on their cellular localizations, protein structures and molecular modes of action.

\section{Experimental procedures}

\section{Bacterial strains and culturing conditions}

The bacterial strains used in this work are listed in Table 1. Escherichia coli K-12 strains JM109 (Sambrook et al., 1989) and ET12567 (MacNeil et al., 1992) were used for propagating plasmids and were grown and transformed using standard procedures (Sambrook et al., 1989).

Streptomyces coelicolor A3(2) and its derivative M145, as well as the developmental (whi) mutants (Table 1), were obtained from the John Innes Centre strain collection and 
adpA mutant M851 from E. Takano (Tübingen, Germany). M145 was used for transformation and propagation of Streptomyces plasmids. Preparation of media, protoplast preparation and transformation were performed according to Kieser et al. (2000). SFM (Soy flour agar plates; Kieser et al., 2000) medium was used to make spore suspensions. Minimal Medium (MM) agar plates containing $0.5 \%(\mathrm{w} / \mathrm{v})$ mannitol, were used for RNA isolation; R2YE agar plates were used for regenerating protoplasts and, after addition of the appropriate antibiotic, for selecting recombinants. For standard cultivation of Streptomyces and for plasmid isolation, YEME or TSBS [tryptone soy broth (Difco) containing 10\% (w/v) sucrose], were used.

\section{Plasmids and constructs}

The plasmids and constructs described in this paper are summarized in Table 2 and a map of the $s s g R A$ gene cluster is shown in Fig. $2 \mathrm{~A}$.

General cloning vectors. plJ2925 (Janssen and Bibb, 1993) is a pUC19-derived plasmid used for routine subcloning. For cloning in Streptomyces we used the shuttle vectors pHJL401 (Larson and Hershberger, 1986), pWHM3 (Vara et al., 1989) and pSET152 (Bierman et al., 1992). All three vectors have the E. coli pUC19 origin of replication; maintenance in streptomycetes occurs via the SCP2* ori (Lydiate et al., 1985) (five copies per chromosome) on pHJL401, the plJ101 ori (50-100 copies per chromosome) on pWHM3 and the attP sequence (allowing integration at the attachment site of bacteriophage $\varphi \mathrm{C} 31)$ on pSET152. Plasmid DNA was isolated from ET12567 prior to transformation to Streptomyces. For selection of plasmids in E. coli ampicillin was used, except for pSET152 (apramycin); chloramphenicol was added for ET12567 transformants. For selection in S. coelicolor we used thiostrepton for pHJL401 and pWHM3 and apramycin for PSET152.

Construction of pGWR2 for in frame deletion of $s s g R$. To create a construct for in frame deletion of $S$. coelicolor ssgR, a 1400 bp Bgll-BamHI fragment containing ssgR and part of $s s g A$ was inserted into BamHl-digested plJ2925 and the approximately $280 \mathrm{bp} \mathrm{Ncol-Sphl} \mathrm{seg-}$ ment of $s s g R$ (Fig. 2A) was removed to create an in frame deletion in the $s s g R$ gene on the plasmid. For this purpose, the DNA was digested with $\mathrm{Ncol}$ and Sphl and the protruding ends were filled in ( $\mathrm{Ncol})$ or removed (Sphl) using T4 DNA polymerase and dNTPs, followed by ligation and transformation. To ascertain we had created an in frame deletion, the DNA sequence was determined and a 279 bp deletion was confirmed. Subsequently, the apramycin resistance cassette aac(C)IV (Kieser et al., 2000) was inserted into the $E c o R I$ site of the construct (outside the $s s g R A$ insert), producing pGWR2. After transformation of the non-replicating construct to S. coelicolor M145, initial integrants (apramycin resistant) were selected, allowed to sporulate on SFM plates without antibiotics and replicated non-selectively to allow a second recombination event to take place and plated for single colonies. The latter were replicated to SFM containing apramycin, to screen for double recombinants, which should have lost the plasmid and hence have become sensitive to apramycin. About $30 \%$ of all apramycin sensitive colonies were

Table 2. Plasmids and constructs. Nucleotide numbering is relative to the start of the respective genes.

\begin{tabular}{|c|c|c|}
\hline Plasmid & Description & Reference \\
\hline pHJL401 & $\begin{array}{l}\text { Streptomyces/E. coli shuttle vector ( } 5-10 \text { and around } \\
100 \text { copies per genome, respectively) }\end{array}$ & Larson and Herschberger (1986) \\
\hline pSET152 & $\begin{array}{l}\text { Streptomyces/E. coli shuttle vector (integrative in } \\
\text { Streptomyces, high copy number in E. coll) }\end{array}$ & Bierman et al. (1992) \\
\hline plJ2925 & $\begin{array}{l}\text { Derivative of pUC19 (high copy number) with Bg/l sites } \\
\text { flanking its multiple cloning site }\end{array}$ & Janssen and Bibb (1993) \\
\hline Q11 & Cosmid clone containing the $s s g R A$ gene cluster & Bentley et al. (2002) \\
\hline pGWR1 & $\begin{array}{l}\mathrm{pHJL} 401+1.3 \mathrm{~kb} s s g R \text { fragment }(-300 /+1000 \text {, relative } \\
\text { to the translational start site of } s s g R)\end{array}$ & This paper \\
\hline pGWR2 & Construct used for creating $s s g R$ deletion mutant. & This paper \\
\hline pGWR3 & $\begin{array}{l}\mathrm{pWHM} 3+1.3 \mathrm{~kb} s s g R \text { fragment }(-350 /+950 \text {, relative to } \\
\text { the translational start site of } s s g R)\end{array}$ & This paper \\
\hline pGWR5 & $\begin{array}{l}\text { pHJL401+1.3 kb fragment harbouring ssfR of } S \text {. griseus } \\
(-300 /+1000 \text {, relative to } s s f R \text { translational start })\end{array}$ & This paper \\
\hline pGWS6 & $\begin{array}{l}\text { plJ2925 harbouring PCR product of oligonucleotides Q10 } \\
\text { and Q11, inserted as a } 237 \text { bp EcoRI-HindllI fragment }\end{array}$ & Van Wezel et al. (2000a) \\
\hline pGWS7 & $\begin{array}{l}\text { pSET152 harbouring S. coelicolor ssgA expressed from } \\
\text { the ermE promoter }\end{array}$ & Van Wezel et al. (2000a) \\
\hline pGWS10 & $\begin{array}{l}\text { pSET152 harbouring } 1.2 \mathrm{~kb} s s g A \text { fragment }(-625 /+540 \\
\text { relative to the translational start site of } s s g A)\end{array}$ & This paper \\
\hline pGWR11 & $\begin{array}{l}\text { pET15b-based construct for the expression and purification } \\
\text { of full-sized SsgR-241 }\end{array}$ & This paper \\
\hline pGWR12 & $\begin{array}{l}\text { pET15b-based construct for the expression and purification } \\
\text { of truncated SsgR-155 }\end{array}$ & This paper \\
\hline
\end{tabular}


sporulation mutants. A check of four sporulating and four non-sporulating double recombinants by PCR revealed that all sporulation mutants carried the expected $300 \mathrm{bp}$ in frame deletion, while sporulating colonies had a wildtype $s s g R$ gene. One of the mutant colonies was selected and designated GSR1. The location of the deletion is shown in Fig. $2 \mathrm{~A}$.

Constructs for complementation experiments. For complementation of the $s s g R$ mutant, plasmid pGWR1 was designed. This low-copy-number pHJL401-based vector harbours the PCR-generated $-350 /+950$ region (relative to the $s s g R$ translational start), including $s s g R$ itself and approximately $300 \mathrm{bp}$ promoter sequences; the oligonucleotides used for PCR were Q16 and Q11 (Table 3), designed such as to add EcoRI and BamHI restriction sites at the ssgR upstream and downstream end, respectively. A multicopy derivative of pGWR1, designated pGWR3, contains the same insert in pWHM3. Plasmid pGWR5 is essentially the same construct as pGWR1, only with the corresponding region of $S$. griseus ssfR instead of $S$. coelicolor ssgR. Plasmids GWS7 and pGWS10 were used for expression of ssgA. pGWS7 (van Wezel et al., 2000a) contains ssgA behind the constitutive ermE promoter in the integrative vector PSET152, while pGWS10 is a pHJL401 derivative, harbouring a $1.2 \mathrm{~kb}$ insert with $s s g A$ preceded by its natural upstream (promoter) region. The insert of pGWS10 was generated by PCR with oligonucleotides Q18 and Q6 (Table 3) and corresponded to the $-625 /+540$ section relative to the start of $s s g A$.

Constructs for the expression of (His) ${ }_{6}$-tagged SsgR. The SsgR expression plasmid pGWR11 was constructed by amplifying $s s g R$ from the $S$. coelicolor genome with Pfu DNA polymerase and oligonucleotides Q2 and Q3(Table 3) and cloned as an Ndel-Hindlll fragment into pET15b, allowing the production of $\mathrm{N}$-terminally (His) ${ }_{6}-$ tagged SsgR; the full sized product was designated SsgR241. For the expression of a truncated version of SsgR (called SsgR-155), containing the N-terminal 155 amino acids of the protein and lacking the TM signature, we made the pET15b-based expression construct pGWR12. The procedure was the same as for pGWR11, except that oligonucleotides Q2 and R155Bam were used (Table 3), the latter introducing a stop codon immediately downstream of the CTC codon for Leu155. The PCR product was cloned as an Ndel-BamHI fragment into pET15b.

\section{Expression and purification of $N$-terminally (His) 6 -tagged SsgR}

Plasmids pGWR11 and pGWR12 were used for the expression of full-sized SsgR (241 aa) and truncated SsgR (155 aa), respectively. For protein expression and purification, BL21 codonplus cells (Stratagene) transformed with either pGWR11 or pGWR12 were grown in LB broth at $30^{\circ} \mathrm{C}$ to an $\mathrm{OD}_{600}$ of about 0.5 , SsgR expression was induced by the addition of $0.1 \mathrm{mM} \mathrm{IPTG}$ and the culture was incubated for a further $4-6 \mathrm{~h}$. Cells were collected by centrifugation at $4^{\circ} \mathrm{C}$ and pellets resuspended in resuspension buffer $(50 \mathrm{mM}$ Tris$\mathrm{HCl} \mathrm{pH} \mathrm{7.5,} 5 \mathrm{mM} \mathrm{MgCl}_{2}, 300 \mathrm{mM} \mathrm{NaCl}$ and $10 \mathrm{mM}$ imidazole). After sonication, the samples were spun down and the supernatant and pellet analysed on a 10-12\% SDS-PAGE gel. Gels were stained with Coomassie Brilliant blue in 7\% ethanol $/ 12 \%$ acetic acid.

Soluble SsgR-155 was purified using Ni-NTA affinity chromatography according to the Novagen protocol and eluted with $200 \mathrm{mM}$ imidazole. Samples were dialysed against stan-

Table 3. Oligonucleotides. Added T7 promoter sequences are underlined, restriction sites used for cloning presented in bold face. Restriction sites: gaattc, EcoRI; aagctt, HindlII; ggatcc, BamHI; catatg, Ndel. The BamHI site in Q11 occurs naturally in $s s g A$, other sites were designed. Location of $5^{\prime}$ end of oligonucleotides (T7 promoter sequences not included) is relative to the start of the gene presented in the last column. The database accession number for whiG is SCO5621, for $\operatorname{rrnA}$ SCO4123.

\begin{tabular}{|c|c|c|c|}
\hline Primer & DNA sequence & Location $5^{\prime}$ end & relative to \\
\hline Q2 & 5'-ctgaattcatatggtgcagcgggcgatgcgcctgctc & +1 & $\operatorname{ssg} R$ \\
\hline Q3 & 5'-ctgaagctttctaacactgatggcatcttgc & +781 & $\operatorname{ssg} R$ \\
\hline Q6 & $5^{\prime}$-ctgaagcttcaccgctgccttgctggccgggtc & +540 & $\operatorname{ssg} A$ \\
\hline Q10 & 5'-ctggaattcagcggttgcagaacgagg & -195 & $\operatorname{ssg} A$ \\
\hline Q11 & 5'-gtacggcatagggatcccgggtctcgtag & +82 & $\operatorname{ssg} A$ \\
\hline Q16 & 5'-ctggaattcgtcgtcgcgcagcgactggtg & -338 & $\operatorname{ssg} R$ \\
\hline Q17 & $5^{\prime}$-ctgggatcctactcgtgctcggcgacgcg & +47 & $\operatorname{ssg} R$ \\
\hline Q18 & $5^{\prime}$-ctggaattcgacaccatggcgcgctgg & -625 & $\operatorname{ssg} A$ \\
\hline R155Bam & 5'-gctaggatcctcagaggggctgcaccgggtagcggtc & +465 & $\operatorname{ssg} R$ \\
\hline T7-AF & 5'-tcggctaatacgactcactatagggatgcggaaagagagctcctc & +41 & $\operatorname{ssg} A$ \\
\hline T7-Rrev & $5^{\prime}$-gcaagttcatgtcgagctcgt & -358 & $\operatorname{ssg} R$ \\
\hline T7-RF & 5'-tcggctaatacgactcactatacggagccgatcagagtcgcggac & +1 & $\operatorname{ssg} R$ \\
\hline ssgA-RT-for & $5^{\prime}$-atgagctttctcgtgtccgagg & +1 & $\operatorname{ssg} A$ \\
\hline ssgA-RT-rev & $5^{\prime}$-cagcggcaccagcttgtcggtg & +325 & $\operatorname{ssg} A$ \\
\hline whiG-RT-for & $5^{\prime}$-ggaacagctgatcctgcactac & +141 & whiG \\
\hline whiG-RT-rev & $5^{\prime}$-tcgcgtacgcgcgctccacgttg & +418 & whiG \\
\hline 16S-RT-for & 5'-tcacggagagtttgatcctggctc & +20 & $r r n A$ \\
\hline 16S-RT-rev & $5^{\prime}$-cccgaaggccgtcatccctcacgc & +436 & $r r n A$ \\
\hline
\end{tabular}


dard buffer (50 mM Tris pH 7.5, $40 \mathrm{mM} \mathrm{NH}_{4} \mathrm{Ac}, 10 \mathrm{mM} \mathrm{MgCl}$, $1 \mathrm{mM}$ DTT).

Inclusion bodies containing SsgR-241 were harvested by centrifugation at $15000 \mathrm{~g}$, solubilized and purified using the Pierce 6xHis B-Per kit, according to the manufacturer's instructions. After purification of SsgR-241 under denaturing conditions using Ni-NTA affinity chromatography, the purified protein was dialysed against standard buffer.

\section{Mobility-shift assay}

Binding of SsgR to target DNA was studied in the following binding buffer: $20 \mathrm{mM}$ Tris- $\mathrm{HCl}(\mathrm{pH} 7.4), 100 \mathrm{mM} \mathrm{KCl,} 5 \mathrm{mM}$ $\mathrm{MgCl}$, $1 \mathrm{mM}$ EDTA, $1 \mathrm{mM}$ DTT and 5\% glycerol. To minimize non-specific interactions, $50 \mathrm{ng}$ of pBR322 and $100 \mu \mathrm{g} \mathrm{ml}^{-1}$ BSA were added. Reaction mixtures $(20 \mu \mathrm{l})$ contained $3 \mathrm{nM}$ $\left[{ }^{32} \mathrm{P}\right]$-labelled DNA probe and $2 \mu \mathrm{l}$ of diluted protein fraction (between 1 and $20 \mathrm{ng}$ ). After $10 \mathrm{~min}$ incubation at $30^{\circ} \mathrm{C}, 2 \mu \mathrm{l}$ dye $(50 \%$ glycerol, $0.25 \%$ xylene cyanol and $0.25 \%$ bromophenol blue) was added and samples were analysed on a non-denaturing $6 \%$ polyacrylamide gel in $1 \times$ TBE buffer. The DNA probe used was produced by PCR using oligonucleotides Q10 and [ ${ }^{32} \mathrm{P}$ ]-labelled Q11 (Table 3) and corresponded to the $-195 /+41$ region relative to the ssgA translational start, similar to ssgA-S1 (Fig. 2A). Electrophoresis was carried out at $4^{\circ} \mathrm{C}\left(4 \mathrm{~h}\right.$ at $\left.15 \mathrm{~V} \mathrm{~cm}^{-1}\right)$. After drying, gels were analysed in a phosphor-imager (Bio-Rad).

\section{PCR conditions}

PCRs were performed in a minicycler (MJ Research, Watertown, MA), using Pfu polymerase (Stratagene, La Jolla, LA) and the buffer provided by the supplier, in the presence of $5 \%(\mathrm{v} / \mathrm{v}) \mathrm{DMSO}$, with annealing temperature of $58^{\circ} \mathrm{C}$. For oligonucleotides see next section and Table 3.

\section{Transcript mapping and probes}

Mycelium was grown on MM or SFM agar plates with mannitol $(0.5 \% \mathrm{w} / \mathrm{v})$ as the carbon source, by plating spores onto presterilised cellophane discs. The RNA was purified from the surface-grown mycelium using the Kirby-based protocol (Kieser et al., 2000), except that DNasel treatment was used in addition to salt precipitation to fully eliminate DNA from the nucleic acid preparations. Phase-contrast light microscopy was used to assess the developmental stage of the surfacegrown mycelium prior to harvesting and RNA isolation. Appropriate primers were labeled at their $5^{\prime}$ ends with $\left(\gamma^{-32} P\right)$ ATP by using T4 polynucleotide kinase before DNA probes were produced by PCR, after which high-resolution S1 nuclease mapping was carried out according to previously described protocol (Kieser et al., 2000). Alternatively $\left(\alpha{ }^{32} P\right)$ UTP-radiolabelled RNA probes were produced with T7 RNA polymerase according to the Maxiscript kit (Ambion) and RNA protection assays were carried out using the RPAIll kit (Ambion). For each RNA protection assay, excess of probe was hybridized to $30 \mu \mathrm{g}$ of RNA. Protected fragments were analysed on denaturing $6 \%$ polyacrylamide gels, where desired alongside a DNA sequencing ladder, produced using the T7 sequencing kit (Amersham Pharmacia Biotech), with as sequencing primers the downstream primers used for generating the PCR-based $s s g A$ and $s s g R$ probes.

Probes used for transcript mapping were produced by PCR, using oligonucleotides described in Tables 3, (i) ssgRT7, a T7 RNA polymerase-generated RNA probe with incorporated $\left(\alpha-{ }^{32} \mathrm{P}\right)$-UTP, produced from a PCR fragment made using oligonucleotides T7-RF and T7-Rrev; the probe was designed against the $-358 /+1$ region (relative to the $s s g R$ translational start); (ii) ssgR-S1, a DNA probe encompassing the $-338 /+47$ region (relative to the $s s g R$ translational start), generated by $\mathrm{PCR}$ with oligonucleotides $\mathrm{Q} 16$ and ${ }^{32} \mathrm{P}$ labelled Q17; (iii) ssgA-T7, a T7 RNA polymerase-generated RNA probe with incorporated $\left(\alpha-{ }^{32} \mathrm{P}\right)$-UTP, produced from a PCR fragment made using oligonucleotides T7-AF and Q10; the probe was designed against the $-195 /+41$ region relative to the $s s g A$ translational start; (iv) ssgA-S1 was generated by PCR on plasmid pGWS6, using ${ }^{32} \mathrm{P}$-labelled Q11 and the 17-mer universal ('forward') pUC primer and corresponded to the $-195 /+82$ region (relative to the $s s g A$ translational start); the probe contains an approximately $50 \mathrm{nt}$ non-homologous $3^{\prime}$ extension to discriminate between full-length protection by RNA and experimental artefacts due to probe reannealing.

\section{RT PCR analyses}

RT-PCR analyses were carried out using the SuperScript III one-step RT-PCR System (Invitrogen) for the analysis of RNA. RNA was isolated from mycelium grown on SFM agar plates with a cellophane overlay, on which all strains sporulated well (M145, M851) or a bit (ssgR mutant). The samples were prepared after $24 \mathrm{~h}, 48 \mathrm{~h}$ and $96 \mathrm{~h}$, corresponding to vegetative growth, aerial growth and sporulation, respectively. For each RT-PCR reaction $1 \mu \mathrm{g}$ of RNA was used together with $0.5 \mu \mathrm{M}$ (final concentration) of each primer. The programme used was as follows: 30 min cDNA synthesis at $55^{\circ} \mathrm{C}$, followed by 40 cycles of: $15 \mathrm{~s}$ at $94^{\circ} \mathrm{C}$ (denaturing), $30 \mathrm{~s}$ at $56^{\circ} \mathrm{C}$ (annealing) and $60 \mathrm{~s}$ at $68^{\circ} \mathrm{C}$ (elongation). The reaction was completed by $5 \mathrm{~min}$ incubation at $68^{\circ} \mathrm{C}$. Samples were tested on a $2 \%$ agarose gel in TAE buffer and stained with ethidium bromide. The following combinations of oligonucleotides were used (Table 3): (i) ssgA-RT-for and ssgA-RT-rev for ssgA; (ii) whiG-RT-for and whiG-RT-rev for whiG; (iii) 16S-RT-for and 16S-RT-rev for 16S rRNA (to check the integrity of the RNA preparations). RT-PCR experiments without prior reverse transcription were performed on all RNA samples to assure exclusion of DNA contamination. Data were verified in several independent experiments.

\section{Computer analysis}

Frame analysis was performed using the frameplot program (Ishikawa and Hotta, 1999), sequence alignments were performed using Clustal (Higgins et al., 1996), Blast searches were performed at NCBI (http://www.ncbi.nlm.nih.gov) and transmembrane helix predictions using the TMPred program (http://www.ch.embnet.org/software/TMPRED_form.html).

\section{Acknowledgements}

We are very grateful to S. Horinouchi for sharing unpublished 
data and for providing valuable comments on the manuscript, to E. Takano for providing adpA mutant M851, to R. Amons (LUMC, Leiden) for $\mathrm{N}$-terminal amino acid sequencing of SsgR, and to K. Flårdh, B. Keijser, B. Kraal, E. Takano and E. Vijgenboom for stimulating discussions. This work was supported by a grant from the Royal Netherlands Academy of Sciences (KNAW) to G.V.W., and from the Dutch applied research council (STW) to B.T.

\section{References}

Bentley, S.D., Chater, K.F., Cerdeno-Tarraga, A.M., Challis, G.L., Thomson, N.R., James, K.D., et al. (2002) Complete genome sequence of the model actinomycete Streptomyces coelicolor A3(2). Nature 417: 141-147.

Bierman, M., Logan, R., O'Brien, K., Seno, E.T., Rao, R.N., and Schoner, B.E. (1992) Plasmid cloning vectors for the conjugal transfer of DNA from Escherichia coli to Streptomyces spp. Gene 116: 43-49.

Chater, K.F. (1972) A morphological and genetic mapping study of white colony mutants of Streptomyces coelicolor. $J$ Gen Microbiol Microbiol 72: 9-28.

Chater, K.F. (2001) Regulation of sporulation in Streptomyces coelicolor A3 (2): a checkpoint multiplex? Curr Opin Microbiol 4: 667-673.

Chater, K.F., and Horinouchi, S. (2003) Signalling early developmental events in two highly diverged Streptomyces species. Mol Microbiol 48: 9-15.

Chater, K.F., and Losick, R. (1997) Mycelial life style of Streptomyces coelicolor A3(2) and its relatives. In Bacteria as Multicellular Organisms. Shapiro, J.A., and Dworkin, M. (eds). New York: Oxford University Press, pp. 149-182.

Chater, K.F., Bruton, C.J., Plaskitt, K.A., Buttner, M.J., Mendez, C., and Helmann, J.D. (1989) The developmental fate of $S$. coelicolor hyphae depends upon a gene product homologous with the motility sigma factor of $B$. subtilis. Cell 59: 133-143.

Embley, T.M., and Stackebrand, E. (1994) The molecular phylogeny and systematics of the actinomycetes. Annu Rev Microbiol 48: 257-289.

Flärdh, K., and van Wezel, G.P. (2003) Cell division during growth and development of Streptomyces. In Recent Developments in Bacteriology. Pandalai, S.G. (ed.). Trivandrum, India: Transworld research network, pp. 71-90.

Flärdh, K., Findlay, K.C., and Chater, K.F. (1999) Association of early sporulation genes with suggested developmental decision points in Streptomyces coelicolor A3 (2). Microbiology 145: 2229-2243.

Flärdh, K., Leibovitz, E., Buttner, M.J., and Chater, K.F. (2000) Generation of a non-sporulating strain of Streptomyces coelicolor A3(2): by the manipulation of a developmentally controlled fts $Z$ promoter. Mol Microbiol 38: 737-749.

Galinier, A., Negre, D., Cortay, J.C., Marcandier, S., Maloy, S.R., and Cozzone, A.J. (1990) Sequence analysis of the $i c l R$ gene encoding the repressor of the acetate operon in Salmonella typhimurium. Nucleic Acids Res 18: 3656.

Higgins, D.G., Thompson, J.D., and Gibson, T.J. (1996) Using CLUSTAL for multiple sequence alignments. Methods Enzymol 266: 383-402.
Hindle, Z., and Smith, C.P. (1994) Substrate induction and catabolite repression of the Streptomyces coelicolor glycerol operon are mediated through the GyIR protein. Mol Microbiol 12: 737-745.

Horinouchi, S. (2002) A microbial hormone, A-factor, as a master switch for morphological differentiation and secondary metabolism in Streptomyces griseus. Front Biosci 7: d2045-57.

Ikeda, H., Ishikawa, J., Hanamoto, A., Shinose, M., Kikuchi, H., Shiba, T., et al. (2003) Complete genome sequence and comparative analysis of the industrial microorganism Streptomyces avermitilis. Nature Biotechnol 14: 14.

Ishikawa, J., and Hotta, K. (1999) FramePlot: a new implementation of the frame analysis for predicting proteincoding regions in bacterial DNA with a high $\mathrm{G}$ plus $\mathrm{C}$ content. FEMS Microbiol Lett 174: 251-253.

Janssen, G.R., and Bibb, M.J. (1993) Derivatives of pUC18 that have Bg/l sites flanking a modified multiple cloning site and that retain the ability to identify recombinant clones by visual screening of Escherichia coli colonies. Gene 124: 133-134.

Jiang, H., and Kendrick, K.E. (2000) Characterization of $s s f R$ and ssgA, two genes involved in sporulation of Streptomyces griseus. J Bacteriol 182: 5521-5529.

Kawamoto, S., and Ensign, J.C. (1995) Cloning and characterization of a gene involved in regulation of sporulation and cell division in Streptomyces griseus. Actinomycetologica 9: 136-151.

Kawamoto, S., Watanabe, H., Hesketh, A., Ensign, J.C., and Ochi, K. (1997) Expression analysis of the ssgA gene product, associated with sporulation and cell division in Streptomyces griseus. Microbiology 143: 10771086.

Keijser, B.J., van Wezel, G.P., Canters, G.W., and Vijgenboom, E. (2002) Developmental regulation of the Streptomyces lividans ram genes: involvement of RamR in regulation of the ramCSAB operon. J Bacteriol 184: 44204429.

Kelemen, G.H., Brian, P., Flärdh, K., Chamberlin, L., Chater, K.F., and Buttner, M.J. (1998) Developmental regulation of transcription of whiE, a locus specifying the polyketide spore pigment in Streptomyces coelicolor A3 (2). J Bacteriol 180: 2515-2521.

Kieser, T., Bibb, M.J., Buttner, M.J., Chater, K.F., and Hopwood, D.A. (2000) Practical Streptomyces Genetics. Norwich, U.K.: John Innes Foundation.

Larson, J.L., and Hershberger, C.L. (1986) The minimal replicon of a streptomycete plasmid produces an ultrahigh level of plasmid DNA. Plasmid 15: 199-209.

Lydiate, D.J., Malpartida, F., and Hopwood, D.A. (1985) The Streptomyces plasmid SCP2*: its functional analysis and development into useful cloning vectors. Gene 35: 223235.

MacNeil, D.J., Gewain, K.M., Ruby, C.L., Dezeny, G., Gibbons, P.H., and MacNeil, T. (1992) Analysis of Streptomyces avermitilis genes required for avermectin biosynthesis utilizing a novel integration vector. Gene 111: 6168.

Ohnishi, Y., Seo, J.W., and Horinouchi, S. (2002) Deprogrammed sporulation in Streptomyces. FEMS Microbiol Lett 216: 1-7. 
Pan, B., Unnikrishnan, I., and LaPorte, D.C. (1996) The binding site of the IcIR repressor protein overlaps the promoter of. Acebak J Bacteriol 178: 3982-3984.

Ryding, N.J., Kelemen, G.H., Whatling, C.A., Flärdh, K., Buttner, M.J., and Chater, K.F. (1998) A developmentally regulated gene encoding a repressor-like protein is essential for sporulation in Streptomyces coelicolor A3 (2). Mol Microbiol 29: 343-357.

Sambrook, J., Fritsch, E.F., and Maniatis, T. (1989) Molecular Cloning: A Laboratory Manual. Cold Spring Harbor, New York: Cold Spring Harbor laboratory Press.

Soliveri, J.A., Gomez, J., Bishai, W.R., and Chater, K.F. (2000) Multiple paralogous genes related to the Streptomyces coelicolor developmental regulatory gene whiB are present in Streptomyces and other actinomycetes. Microbiology 146: 333-343.

Strohl, W.R. (1992) Compilation and analysis of DNA sequences associated with apparent streptomycete promoters. Nucleic Acids Res 20: 961-974.

Sunnarborg, A., Klumpp, D., Chung, T., and LaPorte, D.C. (1990) Regulation of the glyoxylate bypass operon: cloning and characterization of iclR. J Bacteriol 172: 2642-2649.

Takano, E., Chakraburtty, R., Nihira, T., Yamada, Y., and Bibb, M.J. (2001) A complex role for the gamma-butyrolactone SCB1 in regulating antibiotic production in Streptomyces coelicolor A3 (2). Mol Microbiol 41: 1015-1028.

Takano, E., Tao, M., Long, F., Bibb, M.J., Wang, L., Li, W., et al. (2003) A rare leucine codon in $a d p A$ is implicated in the morphological defect of bldA mutants of Streptomyces coelicolor. Mol Microbiol 50: 475-486.

Vara, J., Lewandowska-Skarbek, M., Wang, Y.G., Donadio,
S., and Hutchinson, C.R. (1989) Cloning of genes governing the deoxysugar portion of the erythromycin biosynthesis pathway in Saccharopolyspora erythraea (Streptomyces erythreus). J Bacteriol 171: 5872-5881.

van Wezel, G.P., van der Meulen, J., Kawamoto, S., Luiten, R.G.M., Koerten, H.K., and Kraal, B. (2000a) $s s g A$ is essential for correct sporulation of Streptomyces coelicolor A3 (2) and affects hyphal development by stimulating septum formation. J Bacteriol 182: 5653-5662.

van Wezel, G.P., van der Meulen, J., Taal, E., Koerten, H., and Kraal, B. (2000b) Effects of increased and deregulated expression of cell division genes on the morphology and on antibiotic production of streptomycetes. Antonie Van Leeuwenhoek 78: 269-276.

van Wezel, G.P., White, J., Hoogvliet, G., and Bibb, M.J. (2000c) Application of redD, the transcriptional activator gene of the undecylprodigiosin biosynthetic pathway, as a reporter for transcriptional activity in Streptomyces coelicolor A3 (2) and Streptomyces lividans. J Mol Microbiol Biotechnol 2: 551-556.

Yamamoto, K., and Ishihama, A. (2003) Two different modes of transcription repression of the Escherichia coli acetate operon by IcIR. Mol Microbiol 47: 183-194.

Yamazaki, H., Ohnishi, Y., and Horinouchi, S. (2003) Transcriptional switch on of $s s g A$ by A-factor, which is essential for spore septum formation in Streptomyces griseus. $J$ Bacteriol 185: 1273-1283.

Zhang, R.G., Kim, Y., Skarina, T., Beasley, S., Laskowski, R., Arrowsmith, C., et al. (2002) Crystal structure of Thermotoga maritima 0065, a member of the IcIR transcriptional factor family. J Biol Chem 277: 19183-19190. 